\title{
Tinjauan Pencahayaan Buatan Dalam Membangun Suasana Ruang Pada Pameran Tematik
}

\author{
Galih Ghunadi ${ }^{1}$, Dina Fatimah ${ }^{2}$ \\ ${ }^{1,2}$ Desain Interior, Fakultas Desain, Universitas Komputer Indonesia, Bandung \\ Email:1'gghunadi21@gmail.com,22ina.fatimah@email.unikom.ac.id
}

\begin{abstract}
Abstrak: Penelitian ini bertujuan untuk memaparkan tinjauan terhadap pencahayaan buatan yang bertolak ukur pada konsep tematik yang dibawakan pameran sehingga dapat memunculkan atau membangun suasana dan karakter ruang tersendiri. Pencahayaan merupakan salah satu unsur pengikat ruang yang mempunyai fungsi penting dalam menerangi suatu objek benda ataupun aktivitas manusia. Adapun fungsi lainnya adalah untuk membentuk perspesi, warna dan komposisi ruang. Seiring berkembangnya jaman, tuntutan aktivitas manusia lebih kompleks dan dinamis. Sehingga membutuhkan penyesuaian pada objek yang di sinari. Seperti contoh, sumber cahaya alami tidak efisien jika digunakan dalam waktu jangka panjang. sehingga hal ini mempengaruhi efektifitas dalam penggunaannya. lain halnya dengan sumber cahaya buatan yang umumnya digunakan di dalam ruangan, dengan sumber cahaya yang dapat dikendalikan oleh manusia, membuatnya lebih efektif dan efisien secara pemanfaatan. Metode yang digunakan pada penelitian ini adalah analisis deskriptif dengan data kualitatif. Dari hasil analisis pada studi kasus Museum Satwa Jatim Park 2 menunjukan bahwa, desain pencahayaan buatan dan penggunaan warnanya yang berfokus pada pengenalan lingkungan (Environtment) ataupun habitat dari masing-masing satwa, dapat memberikan karakter dan suasana ruangnya secara spesifik, sehingga konsep tema dan storyline yang dipaparkan pameran dapat tersampaikan kepada pengunjung.
\end{abstract}

Kata kunci: Pencahayaan buatan, Suasana Ruang, Pameran Tematik.

Abstract: This study aims to present a review of artificial lighting that contradicts the thematic concepts presented by the exhibition so that it can bring up or build the atmosphere and character of its own space. Lighting is one of the binding elements of space that has an important function in illuminating an object or human activity. As the times evolve, the demands of human activity are more complex and dynamic. So it requires adjustments to the lighted object. The other function is to form perspective, color and spatial composition. For example, natural light sources are inefficient if used in the long run. so this affects the effectiveness in its use. another case with artificial light sources that are generally used indoors, with light sources that can be controlled by humans, making it more effective and efficient utilization. he method used in this research is descriptive analysis with qualitative data. From the results of the analysis in the case study of the Museum of Wildlife Jatim Park 2 shows that, the design of artificial lighting and the use of colors that focus on environmental recognition (environment) or the habitat of each animal, can provide a specific character and atmosphere of the space, so that the concept of the theme and storyline presented by the exhibition can be conveyed to visitors.

Keywords: Lighting, Atmosphere of Space, Thematic Exhibition.

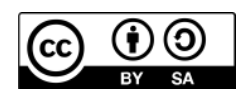




\section{PENDAHULUAN}

Dalam kehidupan sehari-hari pada dasarnya manusia sangat membutuhkan cahaya, seperti cahaya alami dari matahari yang merupakan satu-satunya sumber cahaya untuk menerangi planet bumi. demi kelangsungan hidupnya, manusia memanfaatkan cahaya alami untuk digunakan sebagai kebutuhan dasar bertahan hidup seperti menghangatkan badan, bercocok tanam dan memanfaatkan energinya untuk pembangkit listrik selain itu untuk kebutuhan lainnya seperti menjemur pakaian, menjemur makanan, mengeringkan benda dan lain-lain.

Namun seiring berkembangnya jaman, aktivitas dan kegiatan manusia lebih kompleks dan dinamis, dengan kebutuhan waktu yang semakin panjang dan tidak menentu. Cahaya alami yang pada dasarnya untuk menerangi kebutuhan-kebutuhan dasar manusia di lingkup individu, sekarang tergantikan oleh pencahayaan buatan yang dibutuhkan untuk keperluan individu dan juga massal seperti pada sektor industri, salah satunya di sektor industri kreatif. Hal ini dikarenakan pencahayaan buatan dibuat untuk memenuhi kebutuhan manusia berdasarkan kesesuaian fungsinya dan bersifat fleksibel, tidak bergantung pada waktu.

Pada prakteknya, aktivitas manusia di dalam ruangan lebih banyak mengandalkan pemanfaatan sumber cahaya buatan. Hal ini terjadi karena sumber cahaya buatan relatif dapat dikendalikan sesuai dengan waktu dan jumlah yang diinginkan (Isfiaty, T, 2015).

Perkembangan jaman menjadikan pencahayaan buatan tidak hanya menjadi alat penerangan pada umumnya, namun berkembang menjadi suatu tata kelola cahaya yang dikaitkan dengan unsur estetis dan fungsional. Kebutuhan pencahayaan buatan pada ruang pameran akan menjadi lebih mendominasi di setiap sudut dan titik ruangnya.

Tulisan ini memuat penjelasan dan gambaran secara komperhensif dimana terdapat penjelasan tentang penataan pencahayaan buatan dalam studi kasus museum satwa jatim park 2 dengan ruang pamerannya yang berkonsep tematik (satwa). melalui pengenalan sejarah, cerita, identitas dan konsep ruang yang diambil sehingga mempengaruhi pengambilan penataan cahayanya termasuk jenis dan warna cahaya, jenis dan warna lampu, peletakan, implementasi penerangan terhadap benda pamer, sehingga dapat membangun suasana dan karakter ruang secara keseluruhan.

\section{METODE}

Penelitian ini menggunakan metode analisis deskriptif dengan pendekatan kualitatif. Data yang digunakan pada penelitian ini merupakan data primer dan data sekunder. Analisis desktiptif yang dikemukakan merupakan analisis penataan dan teknis pencahayaaan buatan, yang disimpulkan dan dievaluasi melalui pendekatan kualitatif yakni hal-hal yang dapat membangun suasana dan karakter ruang pada konsep tematik yang dibawakan di museum satwa jatim park 2. 


\section{HASIL DAN PEMBAHASAN}

\section{A. Tinjauan Pencahayaan Buatan}

\section{Sumber Cahaya}

Cahaya merupakan sebuah energi yang memiliki bentuk berupa gelombang elektromaghnetik, dan paket-paket energi dalam bentuk foton (Handayani, E. S, 2019). Pada dasarnya pencahayaan terbagi menjadi dua bagian menurut sumber cahayanya yaitu cahaya alami dan cahaya buatan.

1) Cahaya Alami: merupakan cahaya yang berasal dari alam, seperti matahari dan bulan.

2) Cahaya Buatan: merupakan cahaya yang berasal dari alat penerangan buatan manusia, seperti lampu listrik dan lampu minyak.

Idealnya pencahayaan buatan lebih sering digunakan oleh manusia karena memiliki efektifitas, efesiensi, tidak bergantung pada waktu, jumlah dan bahkan sebaran cahayanya dapat dikendalikan.

\section{Tipe Penerangan Ruang}

Terdapat beberapa tipe penerangan di dalam ruang yang berkaitan dengan fungsi penerangannya terhadap objek sorotnya.

\section{Ambient/General Lighting}

Penerangan umum atau yang disebut juga ambient lighting atau general lighting adalah tipe penerangan yang berasal dari sumber cahaya yang cukup besar dan sinarnya mampu menerangi keseluruhan bangunan atau ruang (Setiawan, B., \& Hartanti, G, 2014).

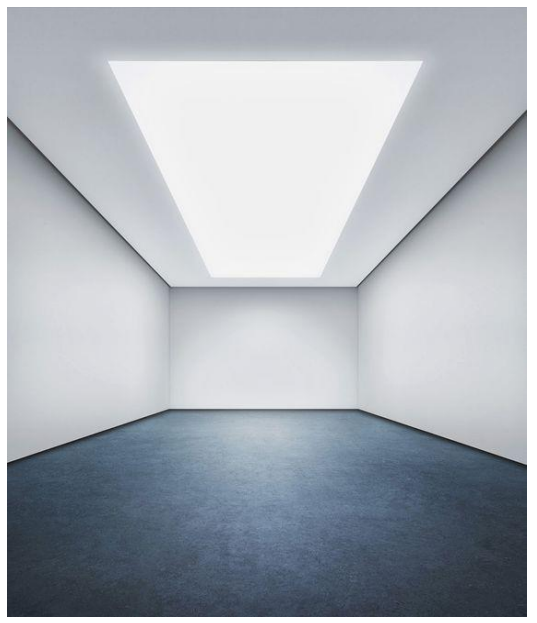

Gambar 1. Implementasi general lighting pada ruang Sumber: Pinterest.com (diakses pada 24 Juli 2020) 


\section{Accent Lighting}

Penerangan aksen atau disebut juga Accent lighting merupakan tipe penerangan yang dikhususkan untuk menyoroti benda yang bersifat dekoratif, seperti benda seni, lukisan, diorama dan lain-lain. Selain sebagai fungsi penerangan, accent lighting berfungsi juga untuk memperindah dan menampilkan unsur estetika pada benda yang disorotnya, general dan accent lighting ini dapat dikombinasikan sehingga menghasilkan bentuk ruang yang tegas, dimensi ruang dan terciptanya karakter atau susasana ruang yang ditonjolkan.

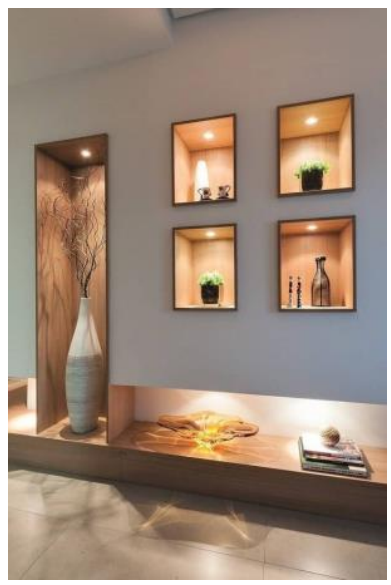

Gambar 2. Implementasi Accent Lighting pada ruang Sumber: Pinterest.com (diakses pada 24 Juli 2020)

\section{Task Lighting}

Penerangan kerja atau disebut juga dengan Task Lighting merupakan tipe penerangan yang mempermudah dan memperjelas pekerjaan secara spesifik seperti membaca, menulis dan memasak. Sehingga dapat membantu lebih fokus pada area kerjanya.

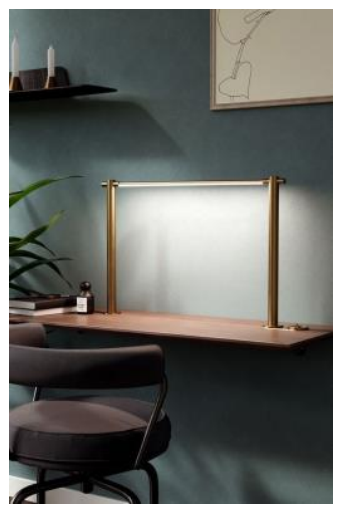

Gambar 3. Implementasi Task Lighting pada ruang Sumber : Pinterest.com (diakses pada 24 Juli 2020) 


\section{Decorative Lighting}

Penerangan Dekorasi atau disebut juga dengan Decorative Lighting merupakan tipe penerangan yang bersifat sebagai objek dekorasi dan lampu tersebut bisa menjadi elemen dekorasi atau menjadi focal point dalam suatu ruang.

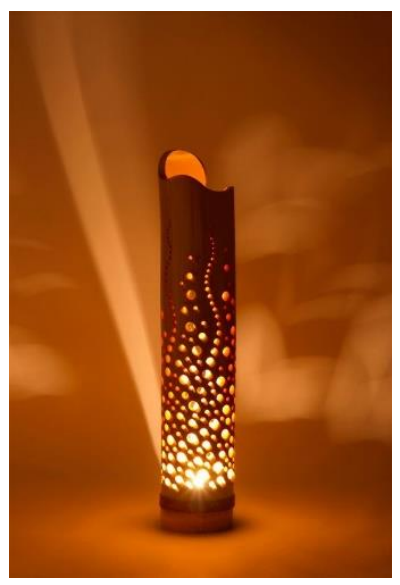

Gambar 4. Implementasi Decorative Lighting pada ruang Sumber : Pinterest.com (diakses pada 24 Juli 2020)

\section{Kinetic Lighting}

Penerangan kinetik atau Kinetic Lgihting merupakan tipe penerangan yagng berasal dari api yang dibentuk sedemikian rupa menjadi obor, lilin dan lentera, sinar penerangan yang tidak begitu konsisten membuat penerangan ini lebih kearah menambah unsur estetis pada ruang.

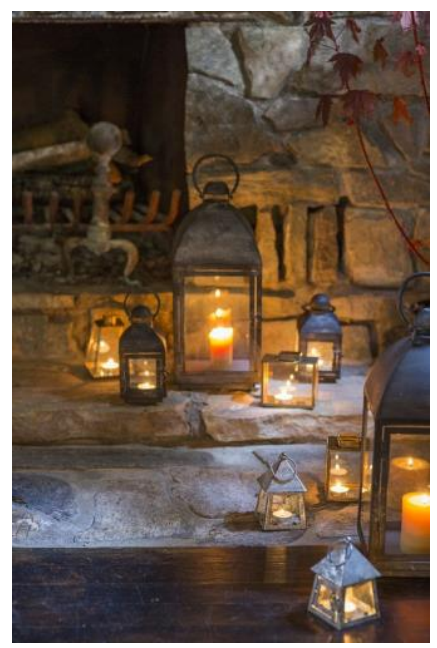

Gambar 5. Implementasi Kinetic Lighting pada ruang Sumber : Pinterest.com (diakses pada 24 Juli 2020) 


\section{Teknik Pencahayaan Ruang}

Teknik pencahayaan ruang terbagi menjadi dua, yakni penerangan langsung dan tidak langsung.

\section{Penerangan langsung/Direct Lighting}

Merupakan teknik penerangan yang ditata untuk menyinari keseluruhan area ruang agar mendapatkan hasil penerangan yang maksimal.

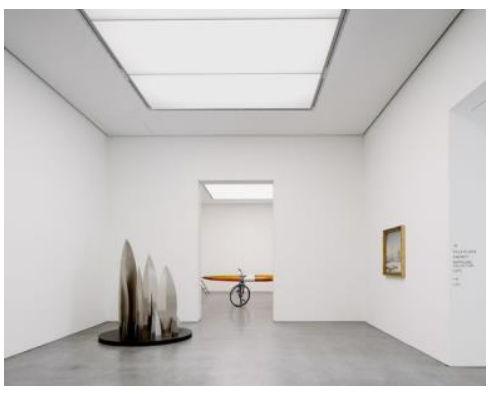

Gambar 6. Teknik Penerangan langsung Sumber : Pinterest.com (diakses pada 24 Juli 2020)

\section{Penerangan Tidak Langsung/Indirect Lighting}

Merupakan teknik penerangan yang menempatkan sumber cahaya lampu secara tersembunyi, sehingga cahaya yang dihasilkan merupakan pantulan atau bias dari sumber cahayanya.

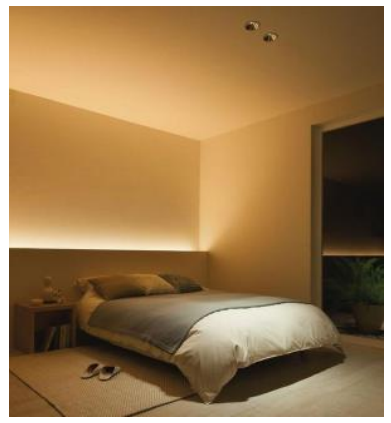

Gambar 7. Teknik Penerangan tidak langsung Sumber : Pinterest.com (diakses pada 24 Juli 2020)

\section{Jenis Penerangan Ruang}

1. Penerangan ke bawah (Downlight)

Penerangan downlight merupakan penerangan dengan arah cahaya ke bawah, umumnya downlight digunakan sebagai general light, akan tetapi bisa juga digunakan sebagai decorative atau accent lighting. 


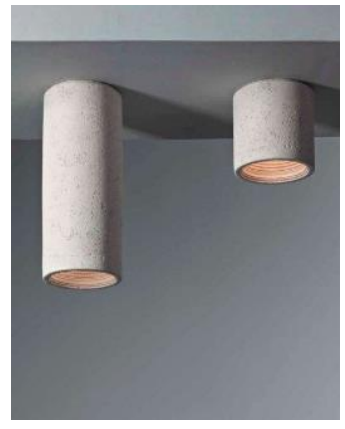

Gambar 8. Jenis penerangan downlight Sumber : Pinterest.com (diakses pada 24 Juli 2020)

\section{Penerangan ke atas (Uplight)}

Penerangan uplight merupakan penerangan dengan arah cahaya dari bawah ke atas. Umumnya pancaran yang diberikan memberikan kesan megah terhadap objek yang disinarinya, seperti kolom dan dinding.

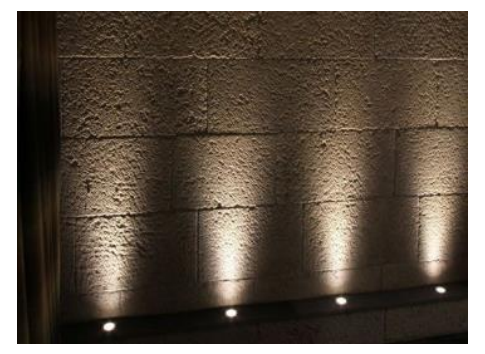

Gambar 9. Jenis penerangan Uplight Sumber : Pinterest.com (diakses pada 24 Juli 2020)

\section{Penerangan dari samping (Sidelight)}

Penerangan sidelight merupakan penerangan dengan arah cahaya dari samping. Umumnya digunakan untuk menyoroti benda seni atau bisa juga sebagai penerangan pada elemen bangunan seperti dinding dan kolom..

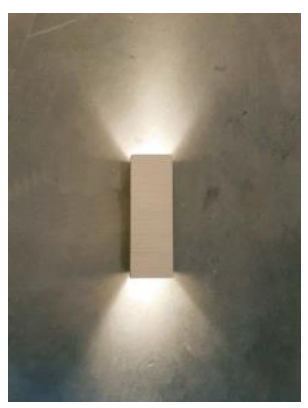

Gambar 10. Jenis penerangan Sidelight

Sumber : Pinterest.com (diakses pada 24 Juli 2020) 


\section{Penerangan dari depan (Frontlight)}

Penerangan frontlight merupakan penerangan dengan arah cahaya yang menyoroti benda seni seperti patung atau lukisan. Fungsinya adalah agar benda seni tersebut lebih menonjol dibanding dengan cahaya yang berada di sekeliling areanya.

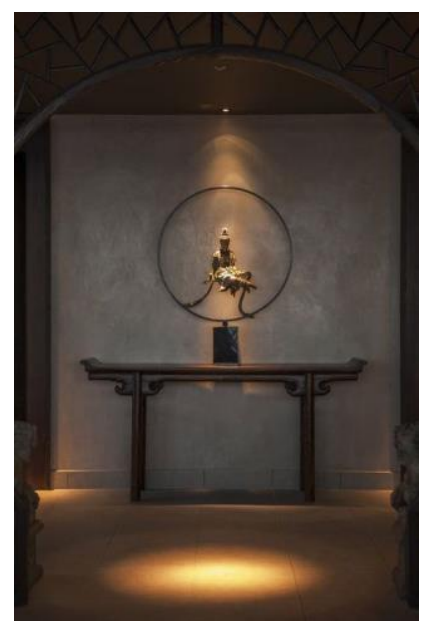

Gambar 11. Jenis penerangan Frontlight Sumber : Pinterest.com (diakses pada 24 Juli 2020)

\section{Penerangan dari belakang (Backlight)}

Penerangan backlight merupakan penerangan dengan arah cahaya dari belakang sehingga menghasilkan siluet dari benda yang disorotinya. Biasanya benda yang disoroti adalah benda seni.

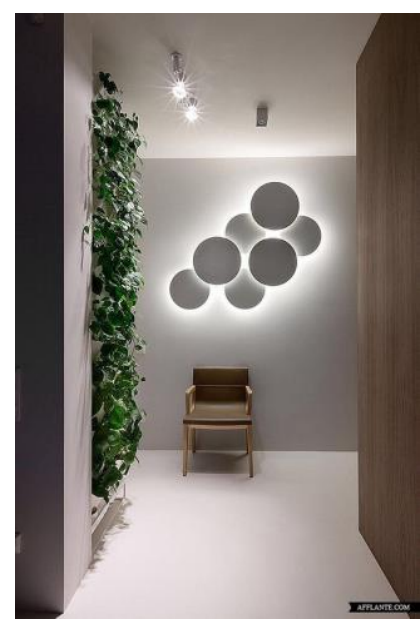

Gambar 12. Jenis penerangan Backlight Sumber : Pinterest.com (diakses pada 24 Juli 2020) 


\section{Wall washer}

Penerangan washer merupakan penerangan dengan arah cahaya yang sengaja dibiaskan pada permukaan dinding ataupun bidang lainnya atau sebagai reflektor, sehingga menghasilkan kesan tekstur yang menonjol dari dinding tersebut.

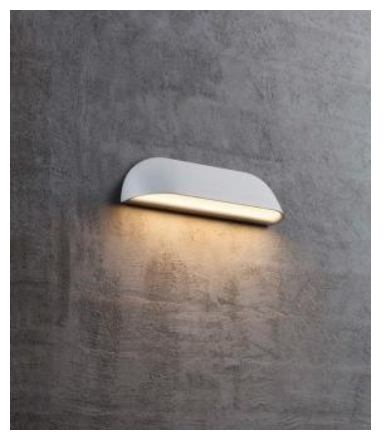

Gambar 13. Jenis penerangan Wall washer Sumber : Pinterest.com (diakses pada 24 Juli 2020)

\section{B. Tinjauan Suasana Raung}

Suasana ruang merupakan unsur pengantar konsep dalam suatu perencanaan ruang. Oleh karenanya kehadirannya sangat penting dalam membantu merepresentasikan konsep dan tema ruang salah satunya melalui stimulasi pada panca indera manusia.

Suasana adalah keadaan sekitar/sekeliling lingkungan yang diterjemahkan dalam unsur-unsur desain yang dapat memenuhi kebutuhan secara fisik dan spritual mengandung nilai-nilai keindahan dan kegunaan bagi si pengguna (Chressetianto, A, 2013).

Suasana ruang adalah suasana yang dipancarkan oleh ruang sebagai lingkungan buatan manusia, merupakan kualitas yang dapat diintervensi dan ditingkatkan sampai batas dan kebutuhan tertentu dan untuk membentuk dampak yang tertentu pula terhadap kegiatan manusia di dalamnya (Hidjaz, T, 2004).

Pada aspeknya menurut Hidjaz, T (2004) Suasana ruang dibedakan menjadi tiga aspek, yaitu lingkungan fisik, psikologik dan sosial.

Komponen fisik pembentuk suasana tersebut adalah unsur-unsur ruang yang merupakan komposisi desain interior. Komposisi tersebut mengandung variabelvariabel kondisi suhu udara, kondisi atmosfir, kondisi nutrisi, kondisi pencahayaan, tingkat kebisingan, obyek-obyek lingkungan dan spasial (Hidjaz, T, 2004).

Dalam membangun suasana ruang, terdapat kaitannya dengan penggunaan warna, baik warna dari material maupun warna dari pencahayaannya. Pemilihan warna untuk setiap ruang sangatlah penting karena masalah tersebut berhubungan dengan penciptaan suasana dan kenyamanan bagi pengguna (Syoufa, A, 2012). 


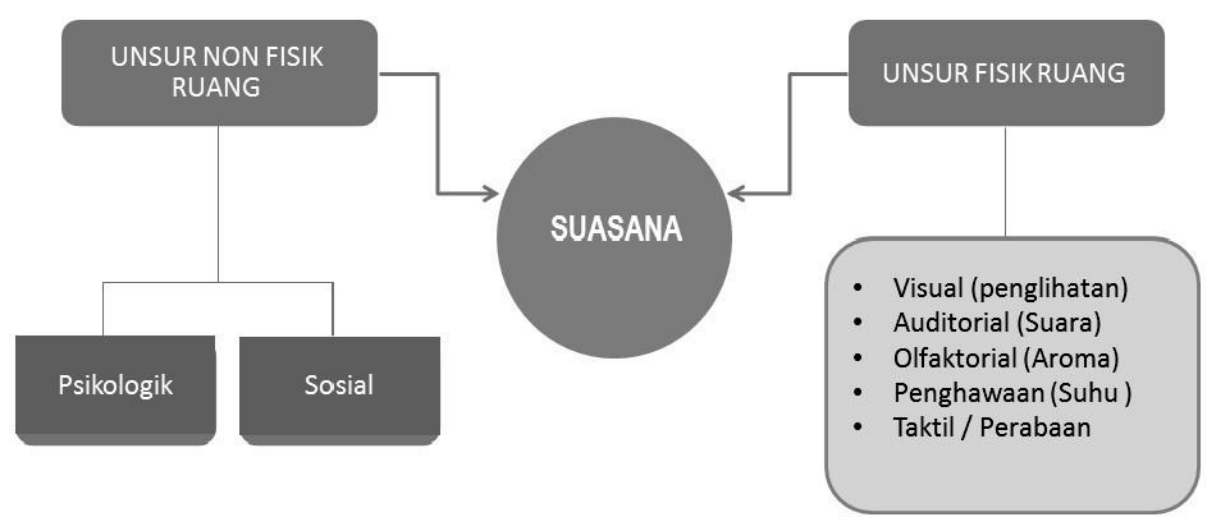

Gambar 14. Elemen Pembentuk Suasana Ruang Sumber : Sarihati, T., Widodo, P., \& Widihardjo, W.(2015)

Dari kesimpulan di atas bahwa untuk membentuk suasana ruang diperlukannya komponen fisik dan non-fisik yang didalamnya salah satunya melalui unsur visual yang diimplementasikan melalui pencahayaan dan warna yang ditata sesuai dengan konsep yang telah dikemukakan.

\section{Tinjauan Museum Satwa Jatim Park 2}

Pameran adalah satu sarana yang dapat memenuhi sifat kodrati manusia, seperti keinginan untuk menonton, mengetahui, memperhatikan sesuatu, mendalami sesuatu, memahami atau menghayati. (Widuri, N. R, 2012).

Secara konseptual, terdapat empat jenis pameran, yaitu pameran tematis, pameran peringatan, pameran institusional dan pameran fungsional. (Pambudi, A. G, 2017).

Pendekatan Tematik, merupakan pendekatan yang lebih menekankan pada cerita dengan tema tertentu dibandingkan dengan koleksinya, menampilkan informasi dengan tema tertentu dan didukung oleh koleksi dan media interaktif. (Ibrahim, dkk, 2018).

Museum Satwa Jatim Park 2 merupakan tempat rekreasi berbentuk pameran tematik yang menyajikan satwa-satwa dan fosil purba sebagai konten dan tema pamerannya, museum ini berlokasi di Kota Batu, Jawa Timur. Museum ini lebih memperlihatkan tema yang diangkat yaitu "satwa" terlihat pada unsur pembangun suasana ruang diimplementasikan melalui pencahayaan pada pamerannya.

Dari Tabel 1 dapat dianalisa bahwa pameran di museum satwa Jatim Park 2, termasuk ke dalam model penekanan Discovery (Penemuan) dengan tipe eksplorasi yang memiliki karakteristik eksplorasi terhadap spesimen yang dikelompokan berdasarkan kategorinya, contohnya adalah untuk kategori hewan mamalia seperti singa, macan tutul, zebra dan jerapah habitatnya adalah di padang savana. 
Tabel 1. Model Penekanan Eksibisi Terhadap Pengunjung Sumber : Modul Penata Pameran Koleksi Museum (2018)

\begin{tabular}{|l|l|l|l|}
\hline Model Penekanan & Tipe & $\begin{array}{l}\text { Pada umumnya } \\
\text { digunakan }\end{array}$ & Karakteristik \\
\hline $\begin{array}{l}\text { Kontemplasi } \\
\text { (perenungan) }\end{array}$ & Estetika & $\begin{array}{l}\text { Museum seni } \\
\text { rupa }\end{array}$ & $\begin{array}{l}\text { Persepsi individual terhadap } \\
\text { karya khusus }\end{array}$ \\
\hline $\begin{array}{l}\text { Komprehensi } \\
\text { (pemahaman) }\end{array}$ & Kontekstual & $\begin{array}{l}\text { Museum } \\
\text { Sejarah, } \\
\text { Arkeologi, dan } \\
\text { etnografi }\end{array}$ & $\begin{array}{l}\text { Persepsi relasional artefak } \\
\text { atau koleksi dalam konteks } \\
\text { atau tema }\end{array}$ \\
\hline $\begin{array}{l}\text { Discovery } \\
\text { (Penemuan) }\end{array}$ & Eksplorasi & $\begin{array}{l}\text { Museum ilmu } \\
\text { pengetahuan } \\
\text { alam }\end{array}$ & $\begin{array}{l}\text { Eksplorasi terhadap spesimen } \\
\text { yang dikelompokkan } \\
\text { berdasarkan kategorinya }\end{array}$ \\
\hline Interaksi & $\begin{array}{l}\text { Demonstrasi } \\
\text { (multimedia) }\end{array}$ & Science Center & Kinestetik respon ke stimulus \\
\hline
\end{tabular}

D. Ringkasan Tinjauan Pencahayaan Buatan Dalam Membentuk Suasana dan Karakter Ruang Pada Pameran Tematik "Satwa" di Museum Satwa Jatim Park 2

Tabel 2. Tinjauan pencahayaan buatan dalam membentuk suasana dan karakter ruang pamer Sumber : Data Penulis (2020)

\begin{tabular}{|l|l|}
\hline $\begin{array}{c}\text { Fasilitas Ruang } \\
\text { Pamer Satwa }\end{array}$ & \multicolumn{1}{|c|}{ Keterangan } \\
\hline $\begin{array}{l}\text { Penggunaan General lighting dengan penggunaan } \\
\text { warna yang ditempatkan secara Indirect } \\
\text { memunculkan atmosfer dan warna ruang yang } \\
\text { berkaitan dengan alam. }\end{array}$ & $\begin{array}{l}\text { Penggunaan tipe Ambience light dan jenis back } \\
\text { light yang dikombinasikan, menghasilkan cahaya } \\
\text { yang temaram, yang mengindikasikan terhadap } \\
\text { atmosfir habitat satwanya. }\end{array}$ \\
\hline & $\begin{array}{l}\text { Perbedaan penggunaan warna pada lighting terjadi } \\
\text { dikarenakan perbedaan tema satwa beserta } \\
\text { habitatnya, sehinga memberikan titik perbedaan } \\
\text { suasana dan atmosfirnya melalui perbedaan } \\
\text { pencahayaan ini. }\end{array}$ \\
\hline
\end{tabular}




\begin{tabular}{|l|l|}
\hline & $\begin{array}{l}\text { Penggunaan Accent lighting dan Uplight } \\
\text { memberikan kesan yang menyatu dengan accent } \\
\text { lighting sebagai unsur penanda objek yang disoroti } \\
\text { dan Uplight yang memberikan kesan dramatis } \\
\text { sekaligus megah pada satwa beruang. }\end{array}$ \\
\hline $\begin{array}{l}\text { Penggunaan jenis penerangan uplight pada bentuk } \\
\text { kolom existing bangunan ruang, memberikan kesan } \\
\text { megah dan mempertegas kesan ruang yang } \\
\text { monumental. }\end{array}$ & $\begin{array}{l}\text { Penggunaan warna lighting dan latar belakang } \\
\text { cahaya back light, membantu menstimulasikan } \\
\text { keadaan dan habitat satwa berada yang seakan-akan } \\
\text { pengunjung sedang berada di gurun pasir yang } \\
\text { panas. }\end{array}$
\end{tabular}

\section{KESIMPULAN}

Kesimpulan dari penelitian ini adalah penataan pencahayaan buatan yang terintegrasi dengan warna, suhu ruang serta storyline dan konsep dari pameran tematik itu sendiri berperan penting dalam menginformasikan, menstimulasikan secara visual, benda pamernya. Sehingga karakter dan suasana dari ruang pameran tematik ini terbentuk dan dapat dirasakan oleh pengunjung secara langsung.

\section{DAFTAR PUSTAKA}

Chressetianto, A. (2013). Pengaruh Aksesoris dan Elemen Pembentuk Ruang Terhadap Suasana Dan Karakter Interior Lobi Hotel Artotel Surabaya. Intra, 1(2).

Handayani, E. S. (2019). Nilai-Nilai Pendidikan Tafsir Sains Dan Komparasi Konsep Cahaya Dalam Disiplin Ilmu Fisika Modern Dengan Konsep Cahaya Kitab Misykat Al-Anwar Karya Imam Al-Ghazali (Doctoral dissertation, IAIN Salatiga).

Hidjaz, T. (2004). Terbentuknya Citra Dalam Konteks Suasana Ruang. Dimensi Interior, 2(1), 51-65.

Ibrahim, Y. A. dkk. (2018). Buku Modul Penata Pameran Koleksi Museum, Jakarta, Direktorat Pelestarian Cagar Budaya dan Permuseuman Direktorat Jenderal Kebudayaan Kementerian Pendidikan dan Kebudayaan.

Isfiaty, T. (2015). Tinjauan Desain Pencahayaan Buatan Interior Selasar Sunaryo Art and Space Bandung. Waca Cipta Ruang. 1. 10.34010/wcr.v1i1.1662. 
Pambudi, A. G. (2017). Dari Sumber Informasi ke Galeri Pengetahuan Pendekatan Kearsipan pada Penyelenggaraan Pameran Arsip Statis. Khazanah: Jurnal Pengembangan Kearsipan, 10(1), 7-17

Sarihati, T., Widodo, P., \& Widihardjo, W. (2015). Penerapan Elemen-Elemen Interior Sebagai Pembentuk Suasana Ruang Etnik Jawa pada Restoran Boemi Joglo. ATRAT: Jurnal Seni Rupa, 3(3).

Setiawan, B., \& Hartanti, G. (2014). Pencahayaan buatan pada pendekatan teknis dan estetis untuk bangunan dan ruang dalam. Humaniora, 5(2), 1222-1233.

Syoufa, A. (2012). Tinjauan pengaruh warna terhadap kesan dan psikis penghuni pada bangunan rumah tinggal. Jurnal Ilmiah Desain \& Konstruksi, 11(2).

Widuri, N. R. (2012). Pameran, Media Komunikasi Antara Perpustakaan Dengan Pengguna. BACA: Jurnal Dokumentasi dan Informasi, 28(2), 120-126. 